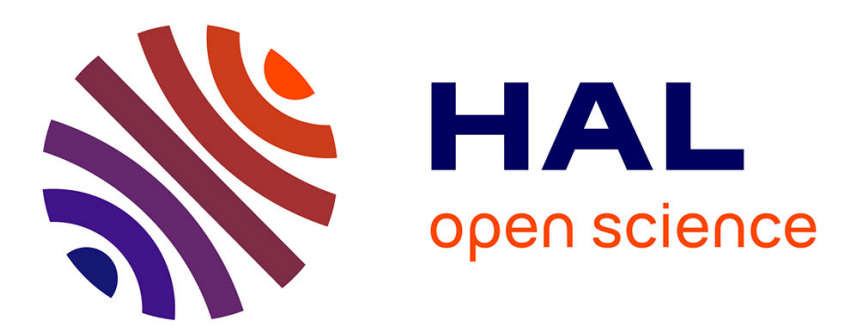

\title{
The interaction of iron and the genome: For better and for worse
}

Marie-Bérengère Troadec, Olivier Loréal, P. Brissot

\section{To cite this version:}

Marie-Bérengère Troadec, Olivier Loréal, P. Brissot. The interaction of iron and the genome: For better and for worse. Mutation Research - Reviews, 2017, 774, pp.25-32. 10.1016/j.mrrev.2017.09.002 . hal-01616421

\section{HAL Id: hal-01616421 \\ https://hal-univ-rennes1.archives-ouvertes.fr/hal-01616421}

Submitted on 24 Oct 2017

HAL is a multi-disciplinary open access archive for the deposit and dissemination of scientific research documents, whether they are published or not. The documents may come from teaching and research institutions in France or abroad, or from public or private research centers.
L'archive ouverte pluridisciplinaire HAL, est destinée au dépôt et à la diffusion de documents scientifiques de niveau recherche, publiés ou non, émanant des établissements d'enseignement et de recherche français ou étrangers, des laboratoires publics ou privés. 
TITLE PAGE

Title: The interaction of iron and the genome: for better and for worse

Authors: Troadec Marie-Bérengère(1)(2), Loréal Olivier(2)(3)*, Brissot Pierre(2)(3)*

\section{Affiliations :}

(1) Institut de génétique et de développement de Rennes, CNRS UMR 6290, Université de Rennes 1, Rennes (France)

(2) SFR Biosit UMS CNRS 3480/US INSERM 018, Rennes (France)

(3) Institut NuMeCan, Inserm U 1241, Université de Rennes 1, Rennes (France)

\section{Corresponding author :}

Marie-Bérengère TROADEC

Institut de Génétique et de Développement de Rennes.

2 Avenue du Pr. Léon Bernard

CS 34317

35043 RENNES CEDEX

FRANCE

E-mail: marie-berengere.troadec@univ-rennes1.fr 
* Senior co-authors having contributed equally to the manuscript.

\section{Content}

1. Human body iron trafficking, homeostasis, and dysregulation

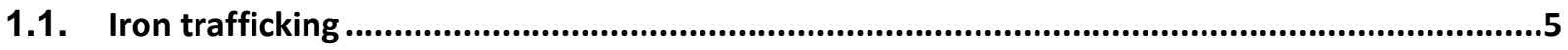

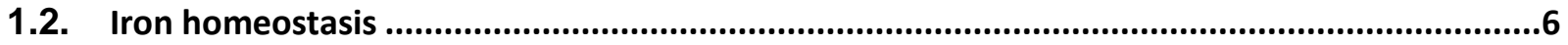

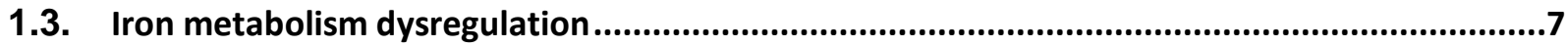

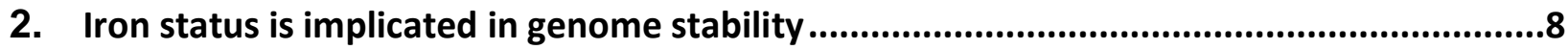

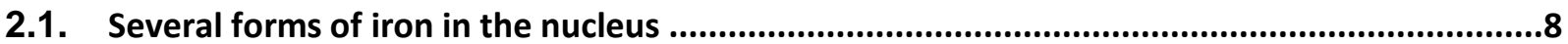

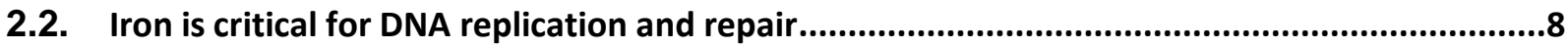

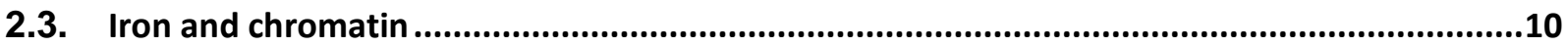

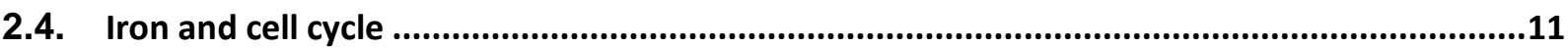

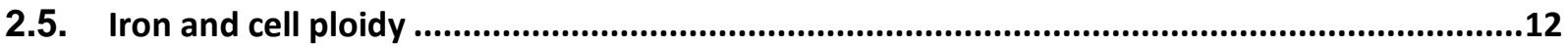

2.6. Iron excess, genotoxicity and consequences in humans .....................................................13

2.7. Iron deficiency may also display genotoxic effect: consequences in humans? ......................14

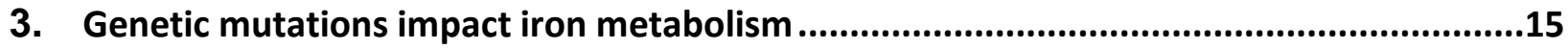

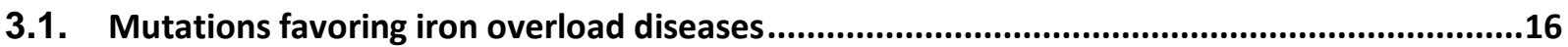

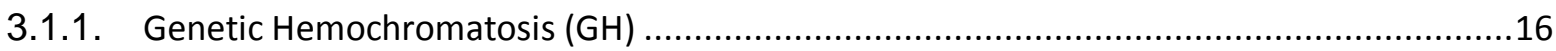

3.1.2. Other diseases with systemic iron overload ..................................................................17

3.1.3. Diseases with relative or compartmental iron excess (iron maldistribution) .....................17

3.2. Mutations causing iron deficiency or with no impact on body iron stores............................18

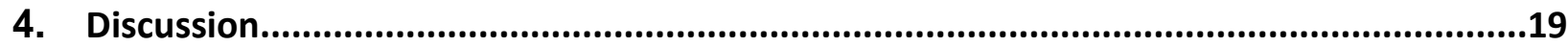




\section{ABSTRACT}

Iron, as an essential nutrient, and the DNA, as the carrier of genetic information which is physically compacted into chromosomes, are both needed for normal life and well-being. Therefore, it is not surprising that close interactions exist between iron and the genome. On the one hand, iron, especially when present in excess, may alter genome stability through oxidative stress, and may favor cell cycle abnormalities and the development of malignant diseases. The genome also receives a feedback signal from the systemic iron status, leading to promotion of expression of genes that regulate iron metabolism. Conversely, on the other hand, DNA mutations may cause genetic iron-related diseases such as hemochromatosis, archetype of iron-overload diseases, or refractory iron deficiency anemia (IRIDA).

Keywords: iron, chromosomes, DNA, reactive oxygen species, mutations, telomeres, hemochromatosis, IRIDA (iron refractory iron deficiency anemia), malignancy. 
The interaction of iron and the genome: for better and for worse

Iron is an essential nutrient needed for cell life whose dysregulation impacts human well-being(1). The spectrum of biological processes implicating iron is broad and includes oxygen transport, mitochondrial respiration, immune response, xenobiotics biotransformation, lipid and protein metabolisms, cell growth and DNA synthesis. Maintaining a homeostasis of iron that is compatible with cell survival is accomplished through tight regulations at cellular and systemic levels. Abnormal cellular or systemic iron concentrations induce subtle toxicities whose accumulations can affect cell functions and processes including genome stability.

The genome is the support of genetic information. Schematically, in eukaryotes, the genome consists of DNA molecules compacted around proteins, assembled into chromosomes that are duplicated and separated during mitosis. In addition, mitochondrial DNA is transmitted from mother to children. Here again, the genome stability -the faithful transmission of genome from generation to generation- is ensured by strict mechanisms.

The purpose of this review is to explore the crosstalk between iron and the genome, both entities requiring tight regulation and stability. The interactions between iron and the genome are numerous, and can be considered in two opposite yet complementary ways. On the one hand, iron status is implicated in chromosome maintenance -especially in telomere length-, as well as in genome stability, and is likely a key actor in human evolution. On the other hand, genetic mutations in various loci can lead to modifications in iron metabolism and are potential causes of human diseases mainly characterized by iron overload, iron deficiency or iron maldistribution. When considering iron and the genome, instability of one may lead to destabilize the other.

We mainly focus the present overview to humans, citing animal models to highlight conserved mechanisms within mammals, especially when discussing iron metabolism. In the first part, we briefly introduce the major systems of iron homeostasis. In the second part of the review, we examine the role 
of iron on genome stability and the ensuing consequences of iron dysregulation on genome stability and cell cycle progression. Finally, on the third part, we expose the main genetic mutations that disrupt iron homeostasis.

\section{Human body iron trafficking, homeostasis, and dysregulation}

\subsection{Iron trafficking}

The sole source of iron is alimentary (10-20 mg per day). Iron is absorbed at the duodenal level at a rate of 1-2 mg per day. This absorption process involves many proteins (1) (Figure 1). First, DCYTB (duodenal cytochrome B, official gene symbol CYBRD1) reduces non heminic Fe(III) ferric iron into Fe(II) ferrous iron (the only iron redox form able to cross membranes). Then, DMT1 (divalent metal transporter 1) carries the iron through the luminal membrane of the enterocyte. In parallel, heminic iron is taken up using independent mechanisms that could involve the heme carrier protein 1 (HCP1) protein, encoded by SLC46A1 gene, and is released from heme by heme oxygenase. Once iron has crossed the cell and reached the plasma basolateral membrane, it is exported into the plasma by ferroportin (official gene symbol SLC4OA1 gene), the only known cell iron exporter. Iron is subsequently re-oxidized by hephaestin (official gene symbol HEPH gene) so that iron can be taken up by transferrin, the plasma iron transporter. Most plasma iron (about $80 \%$ ) targets the bone marrow, enters the erythroblasts (the red blood cell progenitors) through the transferrin receptor1 and transferrin cycle pathway. This iron contributes to the emergence of new red blood cells (also known as erythrocytes), being integrated within hemoglobin for oxygen transport and delivery purposes. At the end of their life, red blood cells are degraded within spleen macrophages, in a process which releases their iron content. This iron is recycled into the plasma through the ferroportin channels, then, is linked again to transferrin, thanks to the ferroxidase activity of ceruloplasmin -instead of hephaestin- for the required oxidation process. Then, the transferrin iron is delivered to the bone marrow through an efficient recycling process. A small 
part of absorbed iron (20\%) targets other organs and participates to multiple biological reactions. Indeed, inside those targeted cells, iron can be located within molecules of ferritin, which acts both as a storage protein -to protect the cytosol from the toxicity of "free" iron- and as a reservoir from which iron can be released depending on cellular and body iron needs. Finally, daily body iron losses are minimal through intestinal cell exfoliation, skin, biliary and urine losses, and are quantitatively equal to absorbed iron (1-2mg per day).

\subsection{Iron homeostasis}

The vital necessity for the human body to maintain adequate iron stores explains a finely tuned regulation of iron. Two main complementary systems ensure this regulation (1): a systemic regulation of iron that involves the hepcidin-ferroportin duo, and a cellular regulation of iron metabolism that relies on IRE/IRP system.

The hepcidin-ferroportin duo is crucial for systemic regulation of iron. Hepcidin, mainly produced by the liver, is the iron hormone (2-4). Whenever plasma iron concentration or body iron stores decrease, hepcidin synthesis decreases in order to counteract this iron deficiency. This feedback mechanism involves two main effects, which are both related to the "stimulation" of ferroportin. On the one hand, intestinal iron absorption is enhanced; on the other hand, there is an increased release by the spleen of the iron coming from the normal degradation of old red blood cells. As a global result, plasma iron increases in order to compensate the initial iron decrease. A reverse mechanism occurs in case of increased plasma iron concentration or body iron stores. It should be noticed that this systemic regulation does not significantly impact body iron losses that are known to be very poorly adaptable.

The IRE/IRP system is responsible for the local cellular regulation of iron metabolism(5). When cellular iron content decreases, the physical interaction of IRP (iron regulatory protein) with IRE (iron responsive 
element), located at the $5^{\prime}$ non coding region of L-ferritin mRNA, is increased, leading to decreased ferritin translation. This leads to decrease the cellular iron storage capacity. Simultaneously, IRP interaction with IREs, located at the $3^{\prime}$ extremity of transferrin receptor1 mRNA, is increased leading to increased stability of transferrin receptor 1 mRNA. Therefore, it results in an increased capacity of the cell for taking up iron from the plasma. These two combined mechanisms concur to compensate the initial decrease of cellular iron content. The reverse mechanism occurs when cellular iron content increases. Altogether, the genome receives a feedback signal from the systemic iron status, leading to promotion of expression of genes that regulate iron metabolism.

\subsection{Iron metabolism dysregulation}

When dealing with the main clinical consequences of human iron dysregulation (other than those related to genotoxicity), three different cases of dysregulation have to be considered: iron deficiency, iron overload and iron maldistribution. Whatever the cause of body iron deficiency is -including poor dietary intake, intestinal malabsorption or increased blood losses-, the major consequence of body iron deficiency is anemia characterized by the anemic syndrome: fatigue, palor, decreased blood pressure, tachycardia(6). Other complications can be however observed including hair loss, spoon nails and dry skin. Whatever the cause of body iron overload is -acquired (multiple transfusions in chronic anemia, excessive parenteral iron supplementation) or genetic (hemochromatosis, most frequently related to HFE gene mutations)-, the iron overload syndrome involves some common clinical consequences such as chronic fatigue, hyperpigmentation, liver, pancreas, pituitary, and heart damage $(7,8)$. Finally, even if total body iron is normal, iron tissue distribution may be inappropriate. Corresponding clinical situations may associate excess of iron in some specific cells in which iron is sequestrated and iron deficiency within other cells. For instance, this case is observed during chronic inflammation. Moreover, isolated iron accumulation in specific cell types can be observed as described in Friedreich Ataxia(9). 
Globally, human iron metabolism dysregulation is responsible, throughout the world, for frequent and severe morbidity and mortality, and therefore generates significant public health problems(10).

\section{Iron status is implicated in genome stability}

\subsection{Several forms of iron in the nucleus}

Nuclear iron has been found in several forms (11). Iron deposits, associated with ferritin, can be detected in the nuclei of iron overloaded mice. Those mice showed larger hepatocyte nuclei than control mice (12). Ferritin has also been identified in the nucleus of K562 cells (13). Additionally, iron can be found into iron-sulfur clusters associated with DNA repair enzymes and transcription factors. Therefore, abnormal variation in iron concentration may not only interfere with appropriate enzymatic functions controlling genome integrity, but also may participate in direct genotoxicity by generating reactive oxygen species (ROS) (Figure 2). The role of iron on the genome stability is critical at different levels: DNA, chromatin, nucleus, cell cycle progression and cell ploidy.

\subsection{Iron is critical for DNA replication and repair}

Numerous proteins involved in DNA replication and DNA repair processes require iron as a cofactor making cell cycle progression, and especially accurate S-phase completion, dependent on iron. Consequently, lack of iron may impede reliable enzymatic activity of these proteins -DNA helicases, polymerases, primases, ribonucleotides reductases-, and weaken genome stability(14).

In particular, some important DNA helicases contain a conserved iron-sulfur (Fe-S) cluster and are key factors for preserving genome stability (review in (15), (16)). For example, XPD helicase (whose official 
gene symbol is $E R C C 2$ ) plays an important role in nucleotide excision repair, and mutations in the helicase domain containing the Fe-S cluster abolish XPD DNA repair activity.

Normal DNA replication is extremely accurate. This accuracy relies on the double function of DNA polymerases: a $5^{\prime}$ to $3^{\prime}$ polymerase activity that elongates a DNA strand, and a proofreading activity. Furthermore, additional enzymes are essential for DNA replication, such as the primase enzyme that synthesizes a strand of nucleic acid complementary to the template strand, priming DNA synthesis. Interestingly, all DNA polymerases and primases require an iron-sulfur (Fe-S) cluster for protein activity, so that iron appears essential for a faithful genome duplication, and thus for maintenance of genome integrity (17).

Finally, by reducing ribonucleotides to deoxyribonucleotides, ribonucleotide reductase enzymes produce the precursors necessary for DNA replication and repair. Ribonucleotide reductase M2 subunit requires iron as a cofactor as well. The consequence of the deficiency in ribonucleotide reductase activity is the arrest of the cell cycle. The mechanisms involved are unclear. If the ribonucleotide deficiency is balanced, as modelized in yeast with the ribonucleotide reductase inhibitor hydroxyurea, the studies suggest that cells have a mechanism for arresting DNA chain elongation when deoxyribonucleotides levels are not maintained above a critical threshold (18). Hydroxyurea treatment has also been shown to reduce more specifically the purine deoxyribonucleotide pool in a variety of mammalian cells (19-22). On the contrary to balanced deficiency of ribonucleotide pool, Kumar et al. show that imbalanced deoxyribonucleotide pools in yeast can lead to DNA mutations and breaks, and to cell death (23).

Altogether, iron status variation impacts DNA duplication and repair by affecting the enzymatic activities of proteins involved in those processes, mostly through Fe-S cluster variation. 


\subsection{Iron and chromatin}

In aqueous solution, it has been demonstrated that $\mathrm{Fe}(\mathrm{II})$ and $\mathrm{Fe}(\mathrm{III})$ cations strongly interact with DNA bases and the backbone phosphate group. Fe(II) binding may cause a minor helix destabilization, whereas Fe(III) may induce DNA condensation. No major DNA conformational changes occurred upon iron complexation (24). In vivo, using elemental mapping analysis to illustrate the distribution of iron in the nucleus, Bertonconi et al. (25) showed that, in Fe(III)-nitrilotriacetate (FeNTA) iron-overloaded fibroblasts, iron is concentrated in chromatin grains, in the nucleoli and in the nuclear membrane region. One function of iron bound to chromatin could be to participate in the maintenance of chromosome structure (26). Additionally, preferential sites of iron-DNA interaction are localized in upstream regulatory regions of many genes involved in oxidative stress (27). Those sites are highly sensitive to iron-mediated oxidative reaction (27). Finally, iron may play a role in telomere length (noncoding fragments at the end of chromosomes) control. These non-coding ends of chromosomes are shortened during cell division and can be considered as ageing biomarkers. First, some Fe-S cluster helicases are involved in telomere maintenance. The helicase RTEL (for Regulator of TELomere), through its interaction with the shelterin complex, whose function is to protect telomeres from DNA repair mechanisms and from telomerase activity, contributes to telomere maintenance (15). Second, telomeres have been shown to be more subjected to strand breakage than similar-sized coding control fragment - the breaks were generated by Fe(II) mediated oxidative reaction (also known as the Fenton reaction) (28). Shortening of telomeres is then a possible consequence of oxidative stress, itself favored by iron. Contrasting with the results of Brown et al.(29) who did not find telomere shortening in iron overloaded rats, other data do support an iron-induced shortening effect. In a series of 669 human adults (30), a correlation was found between increased plasma transferrin saturation levels and shorter leukocyte telomere length together with decreased health status. When considering patients with an HFE genotype, i.e. patients presenting the p.Cys282Tyr HFE mutation (31), the correlation was found only with those presenting a positive iron phenotype, defined by an increase of both plasma transferrin 
saturation and ferritin (32). These results might link oxidative damage and iron load to telomere shortening and ageing.

\subsection{Iron and cell cycle}

Cell cycle progression involves successive steps: G0 exit and entry in cell cycle, G1 restriction point transition, DNA synthesis, G2 phase, mitosis, G0 entry or G1 phase entry for an additional cell cycle. Primary cultures of hepatocytes from iron-overloaded mice showed an early entry in G1 and an independence to mitotic stimuli for the G1 restriction point transition (33). DNA synthesis is also exacerbated after iron overload. In primary rat hepatocyte cultures stimulated by EGF/pyruvate, Chenoufi et al. (34) showed that iron enhanced DNA synthesis, likely due to both increased cell proliferation and to DNA repair following iron-induced DNA damage. This mechanism may play a role in the favoring effect of iron on the development of hepatocellular carcinoma in conditions of chronic iron overload. It should be recalled that, in hepatocellular carcinoma, hepatocytes are paradoxically devoid of iron(35), probably due to high iron needs of cancer cells to proliferate $(36,37)$.

Furthermore, mitotic index can be boosted by iron. Hepatocytes of iron overloaded mice showed a mitotic index increase and abnormal mitotic figures (12). Mechanistically, iron modulates cell cycle progression by numerous direct and indirect mechanisms: modulation enzymatic activities, phosphorylation of proteins, expression of genes (review in (38)). For instance, experiments performed under iron chelation or iron overload demonstrated an impact of iron on the phosphorylation of the retinoblastoma protein $(p R b)$ and on the variation of the expression of cyclins $A, B$ and $D, p 53, p 21$ which are critical for cell cycle progression(38-40). Interestingly, it has also been suggested that an unexcessive concentration of iron in tumoral cells may represent a mechanism of defense against ferroptosis, a cell death involving ROS with specific morphologic alterations targeting the mitochondria(41), and therefore may represent a survival advantage for those cells. Therefore the control of iron content in tumor cells is critical for growing. 
In the specific case of yeast meiotic process, using the fission yeast Schizosaccharomyces pombe model, Brault et al. (42) showed that iron is required for normal meiosis progression. Iron deficiency provoked a meiotic arrest at metaphase I. Moreover, the CCAAT regulatory subunit Php4, part of the Php2/3/4/5 transcription complex required to inactivate a subset of genes encoding iron-using proteins (43), plays a key role for iron economy in meiotic cells. Thus, under low iron conditions, functional GFP-Php4 colocalizes with chromosomal material at every meiotic stage whereas iron repletion leads to disappearance of the fluorescence signal. Using a DNA microarray approach, 137 genes were identified as being regulated in an iron- and Php4-dependent manner, 18 of them being exclusively expressed during meiosis(42).

\subsection{Iron and cell ploidy}

As a result of the impact of iron on cell cycle, both iron overload and iron deficiency have been reported to modulate cell ploidy and/or aneuploidy. Liver iron overload in mouse has been shown to increase hepatocyte ploidy $(12,33)$ without affecting the transcript levels of some iron-related genes, which were still correlated with cell DNA content (44). Even if ploidisation of hepatocytes is a physiological event, increase of the number of polyploid cells is still a marker of liver damage including iron overload.

Aneuploidy is known as a condition in which the copy number of a particular chromosome in a karyotype may be increased or decreased as compared to the expected diploid status (46 chromosomes). On the contrary to ploidisation of hepatocytes, aneuploidy is clearly not a physiological event. However, evaluating, in a mouse model, aneuploidy through DNA index (amount of DNA per cell in G0-G1 phase), Kuvibidila et al. (45) reported that iron deficiency may modulate immune functions through increased aneuploidy rate. The mechanisms involved in iron-mediated ploidisation or aneuploidy are still not clear. 
Having exposed the role and the impact of iron on DNA repair and replication, the capacity of iron to bind directly and indirectly DNA and chromatin, and the effect of iron on cell cycle progression, we will now consider more specifically the genotoxicity associated with iron overload, as well as iron depletion.

\subsection{Iron excess, genotoxicity and consequences in humans}

Oxidative stress, generated by ROS (Reactive Oxygen Species) such as the superoxide radical, hydroxyl radical, and $\mathrm{H}_{2} \mathrm{O} 2$ leads to DNA base alterations, single- and double- strand breaks, which are toxic and potentially mutagenic. Iron, a major trigger of oxidative stress, can therefore be deleterious to DNA(46) (review in (16)). In primary cultures of rat hepatocyte, Abalea et al. (47) reported, after ferric nitrilotriacetate (FeNTA) exposure, that DNA was repaired by the flavonoid myricetin antioxidant, demonstrating that DNA damage was due to oxidative effect of FeNTA. Mitochondrial DNA can also be damaged during iron-overload. Using cultured rat cardiac myocytes, Gao et al. (48) showed progressive loss of intact mitochondrial DNA in response to iron-overload. Iron-induced DNA oxidation is not homogenous along the genome, and some hot spots more sensitive to iron-induced DNA oxidation have been identified. Performing a genome wide analysis in a rat model of FeNTA iron-induced renal cell carcinoma, Zhong et al.(49) found, by array-based comparative genomic hybridization and loss of heterozygosity analyses, a common deletion at $8 q 31-32$ chromosomal region, equivalent to a human hot spot frequently present in human cancers. Moreover, combining these data with cDNA results, this study identified a tumor suppressor role for aminoacylase 1 whose gene maps to 8q32. Hemoproteins can also indirectly participate in DNA damage. Those proteins, such as hemoglobin, myoglobin and cytochromes, contain heme as a prosthetic agent. During intracellular heme degradation through heme oxygenase, hydrogen peroxide is produced and can damage DNA (17).

In humans, iron-related genotoxicity is supported by numerous studies which have reported the favoring role of human chronic iron overload, either of genetic or acquired origin, on the development 
of hepatocellular carcinoma $(35,50-52)$. Such a role on the development of extrahepatic cancer remains debated $(53,54)$. Vautier et al. reported the first demonstration of tumor suppressor gene p53 mutation clustering in hepatocellular carcinoma of hemochromatosis patients(55). Studying the frequency of p53 mutated alleles in non tumorous liver from eight hemochromatosis patients, Hussain et al.(56) found higher frequency of $\mathrm{G}: \mathrm{C}$ to $\mathrm{A}: \mathrm{T}$ transversions at codon 249. In thalassemia major, where oxidative stress develops due to postransfusional and dyserythropoietic iron excess, an increase rate of sister chromatid exchange $(57,58)$ and chromosomal aberrations $(58,59)$ have been reported. In thalassemia minor $(58)$, sister chromatid exchange was significantly increased versus healthy controls but not chromosomal aberrations. Ataxia telangiectasia is a rare recessive disorder characterized by progressive ataxia, genomic instability and increased malignancy incidence. The mutated gene (ATM) (chromosome 11q22.3) regulates checkpoints and DNA double stranded break repair. Although this disease is not associated with iron overload, the damaging role of iron, through oxidative stress, has been shown in the $\mathrm{Atm}^{-1}$ - mouse model and in the human disease $(60,61)$. Ataxia telangiectasia cell exposure to labile iron initiated an ATM-dependent G2 checkpoint and suppressed Ataxia telangiectasia colony formation (62). Various iron chelators, among which desferrioxamine, reduced chromosomal breaks in ataxia telangiectasia cells previously exposed to the oxidant t-butyl hydroperoxide.

\subsection{Iron deficiency may also display genotoxic effect: consequences in humans?}

The impact of iron deficiency on chromosomes has been documented both in animal models and in humans. Iron-deficient rats have been reported to exhibit an hepatic increase in 8-hydroxy-2'deoxyguanosine, which, as an adduct of hydroxyl radicals, is a marker of oxidative damage (63). Moreover, iron deficiency in rats has been shown to damage, like iron excess, mitochondrial DNA (64). However, Diaz-Castro et al.(65) studying iron-deficient rats found neither increased lipid peroxidation nor lack of DNA stability. All the mechanisms explaining the generation of oxidative stress under iron depletion are not fully understood. Previous studies have shown that iron deficiency anemia is 
associated with oxidative stress produced by a decrease in antioxidant enzyme activities and/or a high level of oxidants $(63,66)$ (review in (16)).

Because iron deficiency is the most common and widespread nutritional disorder in the world, and is associated to numerous genetic diseases, evidence of iron-depletion induced oxidative stress has been studied in humans. The results are not all concordant. In a group of 22 females with iron deficiency anemia, lymphocyte DNA damage (strand breaks), assessed by the comet assay (single-cell gel electrophoresis) was increased (67). However, these findings were not confirmed by Aksu et al. (68) who found, in 27 children with iron deficiency anemia, a significant decrease of DNA strand breaks (comet assay) and no statistical difference for Fpg (formamidopyrimidine DNA glycosylase)-sensitive sites which reflect the net amount of DNA damage. Accordingly to the study of Aslan et al. (67), in 18 iron deficiency anemia patients, a significant but slight increase in the frequency of spontaneous chromosomal aberrations was found by Khabour et al., without coexisting increase in sister chromatid exchange (69). Discrepancies between those studies may be explained by additional genetic and environmental factors.

Altogether, iron is directly and indirectly involved in chromosome and genome stability, in cell cycle progression through its participation in accurate enzyme activities of key proteins of DNA synthesis initiation, DNA duplication, proofreading, and replication of telomeres. Improper iron status has been reported to alter cell ploidy. Finally, evidences accumulate to highlight the potential genotoxic effect of both iron depletion and iron overload.

\section{Genetic mutations impact iron metabolism}

This domain encompasses iron-related diseases of genetic origin (Table 1). 


\subsection{Mutations favoring iron overload diseases}

\subsubsection{Genetic Hemochromatosis (GH)}

Numerous genetic mutations can be involved in iron overload diseases (70) (Table 1):

Mutations of the HFE gene, located on chromosome 6p22.2, are responsible for the most frequent form of $\mathrm{GH}$ in Caucasian populations, called type $1 \mathrm{GH}$. Homozygosity for the C282Y mutation (official terminology: p.Cys282Tyr) is the highly predominant genetic profile (71). Compound heterozygosity involving the C282Y mutation corresponds usually to an association with the H63D mutation (official terminology p.His63Asp) and is considered as a genetic profile that only predisposes to moderate iron excess in the context of other diseases such as the dysmetabolic syndrome. Exceptional cases of compound heterozygosity where C282Y is associated to other HFE mutations lead to clinically or biochemically expressed GH(72). Non-HFE mutations are involved in rare forms of human iron overload. Mutations in Bone Morphogenetic Protein 6 (BMP6) gene, also on chromosome 6 (6p24.3), have been reported $(73,74)$ associated with mild to moderate late-onset iron overload. Mutations in mouse Bmp6 that induced massive iron overload was previously reported (75). Mutations of the HFE2 or hemojuvelin (HJV) gene (chromosome 19q13.12) are responsible for severe $\mathrm{GH}$ (type $2 \mathrm{~A} \mathrm{GH}$ ) affecting adolescents or young adults ( $<30$ years old), called juvenile GH. Mutations of the hepcidin (HAMP) gene (chromosome 1q21.1) are also responsible for juvenile GH (type 2B GH) (76). Mutations of the TFR2 (transferrin receptor 2) gene (chromosome 7q22.1) are responsible for type $3 \mathrm{GH}$ which mimick type $1 \mathrm{GH}$ (77). Mutations of the ferroportin gene (official gene symbol SLC4OA1) (chromosome 2q32.2) cause type 4 $\mathrm{GH}(78,79)$. Mutations of the ceruloplasmin gene (CP gene) (chromosome 3q25.1), are responsible for hereditary aceruloplasminemia (80), characterized by diffuse body iron overload which, in contrast to the aforementioned GH forms, may also affect the brain. All GH forms, but type 4, have a recessive mode of transmission. The mechanism whereby mutations in types $1,2 \mathrm{~A}$ and $3 \mathrm{GH}$ lead to iron excess mainly involves alterations of the BMP-SMAD signaling pathway with subsequent decreased hepatic synthesis of hepcidin $(2-4,81)$. Hypohepcidinemia is, in turn, responsible for hypersideremia, through 
increased intestinal iron absorption and increased release of splenic iron. An abnormal form of plasma iron appears, called non-transferrin bound iron (NTBI) (82), which is avidly taken up by parenchymal cells(83) and explains that iron overload occurs mainly within the hepatocytes, rather than in Kuppfer cells. When clinically expressed(84), those GH forms can cause chronic asthenia, joint pains, melanodermy, hepatic cirrhosis, diabetes, or cardiomyopathy. Type 4 GH (also named "ferroportin disease") develops (in its usual form) iron overload by a different mechanism which is iron retention, ferroportin being cellular iron exporter. This retention occurs essentially within the reticulo-endothelial system (macrophages), so that iron overload is essentially located in the spleen and, at the hepatic level, in the Kupffer cells. Clinical expression is usually milder than in the other GH forms (85).

\subsubsection{Other diseases with systemic iron overload}

Mutations of the transferrin gene (TF) (3q22.1) are responsible for hereditary atransferrinemia (86), combining iron overload and anemia. Additionally, mutations of the DMT1 gene (SLC11A2 for solute carrier family 11, member 2) (chromosome 12q13.12) lead to microcytic anemia with systemic iron excess -DMT1 being not only involved in intestinal iron absorption but also in iron release from endosomes- $(87,88)$.

\subsubsection{Diseases with relative or compartmental iron excess (iron maldistribution)}

Diseases with relative or compartmental iron excess characterized by iron maldistribution include: i) Friedreich ataxia due to mutations of the frataxin gene (FXN), locus 9q21.11, causing mitochondrial iron accumulation (89) ; ii) Other neurodegenerative disorders (90) such as pantothenate kinase 2 deficiency (gene PANK2 ; locus 20p13)(91) corresponding to the Hallervorden-Spatz syndrome, neuroferritinopathy (gene FTL for Ferritin Light Chain, locus 19q13.33) (92), or phospholipase A2 deficiency (gene PLA2G6, locus 22q13.1)(93) ; iii) Heme synthesis disorders such as congenital sideroblastic anemias (94) by mutations of the following genes: ALAS2 (chromosome Xp11.21), SLC25A38 (chromosome 3p22.1), $A B C B 7$ (chromosome Xq13.3), glutaredoxin 5 (GLRX gene; chromosome $5 q 15$ ). It is noteworthy that, in the case of myelodysplastic syndromes, SF3B1 (splicing factor 3b subunit 1) haploinsufficiency has been 
shown to lead to formation of ring sideroblasts (95). Moreover, patients with SF3B1-mutated myelodysplastic syndromes with ring sideroblasts may harbor a more severe iron overload phenotype (96).

\subsection{Mutations causing iron deficiency or with no impact on body iron stores}

TMPRSS6 (transmembrane serine protease S6) gene encodes, on chromosome 22q12.3, matriptase 2 which is a transmembrane serine protease expressed on hepatocyte cell membranes and is involved in the hepcidin regulatory pathway. TMPRSS6 mutations are responsible for iron refractory iron deficiency anemia (IRIDA) through chronic hyperhepcidinemia $(97,98)$. This disease is characterized by severe microcytic anemia, usually diagnosed during childhood, which is typically refractory to oral supplementation and only partially responsive to parenteral iron. TMPRSS6 polymorphisms have also been associated to iron deficiency anemia that is partially responsive to oral iron supplementation(99). L-ferritin mutations (FTL gene on chromosome 19q13) may cause a dominant inherited disorder (100, 101) expressed by high serum ferritin levels without iron overload. Depending on the mutation location on L-ferritin mRNA, cataract (at a young age) may or not (102), develop.

Finally, some mutations in genes implicated in iron metabolism have been reported in animal model but no human equivalent have been yet described in humans. For instance, Mitoferrin1 knock-out mice or zebrafish (official gene symbol S/c25a37) showed profound anemia because of a deficit in erythroblast formation. In the presence of increased porphyrin synthesis, deletion of Mitoferrin 1 in hepatocytes results in a decreased ability to convert protoporphyrin IX into heme, leading to protoporphyria, cholestasis, and bridging cirrhosis (103). Of note, while studying erythropoietic protoporphyria patients with no abnormal ferrochelatase (FECH) activity, Wang et al. (104) suggests that abnormal Mitoferrin1 expression can contribute to erythropoietic protoporphyria phenotype in some patients, probably by causing a reduction in FECH activity (104). Hephaestin is a multicopper ferroxidase implicated in the uptake of iron emerging from duodenal enterocytes by plasma transferrin. Mutations of the hephaestin gene result in iron deficiency anemia in the sex-linked anemia (s/a) mouse (105). So far, no mutations in 
hephaestin gene have been reported in humans. It is possible that mutants in those genes have not been extensively searched in humans or that mutations are compensated by other genes, masking a frank phenotype.

\section{Discussion}

Iron and DNA are obligatory contributors to normal life. The complexity of iron homeostasis increases along evolution. A recent study by Nuttle et al. (106) showed how closely human chromosomal evolution and iron homeostasis are related. The analysis of the differences between the genomes of humans and closely related primates showed that the duplication of a 95-kilobase-pair segment on chromosome $16 \mathrm{p} 11.2$ containing boLA family member 2 (BOLA2 gene) led to a human specific in-frame fusion transcript. BOLA2 is, therefore, a gene duplicated exclusively in Homo Sapiens. BOLA2 is known to interact physically with GLRX3 (glutaredoxin 3). In yeast, this complex plays a role in iron sensing whilst in vertebrates it is thought to intervene in iron regulation and iron-sulfur protein biogenesis (107). This seminal chromosomal study points out the critical role of iron homeostasis at the root of the divergence between Homo Sapiens lineage and ancient hominins.

Iron metabolism has not yet revealed all its secrets. More remains to be known in terms of iron trafficking such as the precise mechanism of intestinal absorption of heme iron, the possible interactions between hephaestin and ceruloplasmin, the importance of chaperone molecules for transporting iron within the cytosol (108). The precise function of HFE has not been fully elucidated yet. Alterations of iron homeostasis or genome stability may have reciprocal deleterious consequences; from the pathophysiological viewpoint, the mechanisms leading to iron-related cell death may not be solely related to reactive oxygen species-related necrosis but involve the novel concept of ferroptosis (109). The potential role of interactions between iron and other metals should also be considered (81). As to mutations causing iron-related diseases, it is likely that most of them have been identified. However, from our clinical experience, clinical data of genetic iron overload disorders strongly suggest that some rare families, highly suggestive of genetic iron overload, do not fit with the entities described so far. 
Next Generation Sequencing (NGS) may help elucidating those cases. Likewise, for already described genetic iron-related disorders, one major problem remains to explain their phenotypic variability. Beside acquired factors, some additional genetic factors may be involved. Again, using the novel high throughput genetic strategies may be quite helpful, knowing however that those powerful techniques raise the issue of the interpretation of the multiple new discovered mutations in terms of their potential damaging impact. In this regard, setting up appropriate functional validation techniques will be essential.

\section{CONFLICTS OF INTEREST}

Nothing to declare.

\section{ACKNOWLEDGMENTS}

The authors acknowledge the support of CNRS, INSERM, Université de Rennes 1, AHO (Association Hémochromatose Ouest), and AFeMERS (Association Fer-Métaux Essentiels-Recherche-Santé).

\section{FIGURE LEGENDS}

FIGURE 1. Iron trafficking

Ferric iron is taken up by enterocytes by DMT1 after DCYTB-mediated reduction into ferrous iron. At the enterocyte plasma membrane level, iron is exported from enterocyte by ferroportin and hephaestinoxidation. Alternatively, heminic iron is taken up using independent mechanism that could involve HCP1 protein (encoded by SLC46A1 gene). Iron is then transported into blood plasma by binding to transferrin. At the utilization sites, for example, bone marrow, iron-transferrin is internalized by binding 
to transferrin receptor1, and incorporated into iron-bound molecules such as hemoglobin in erythroblasts. Maturation of erythroblasts gives raise to erythrocytes which are - at the end of their lifedegraded by spleen macrophages. Degradation of hemoglobin allows the release of iron through ferroportin and ceruloplasmin oxidation. Plasma iron- once again transported into plasma by transferrincan end up either into ferritin in storage sites, such as in hepatocytes or re-enter the iron utilization cycle. Note that the different elements of the scheme are not at scale.

FIGURE 2: Physiological and pathophysiological iron effects on genome stability.

Iron is physiologically involved in genome stability. In particular, iron is required for the appropriate activities of key enzymes of DNA replication and DNA repair. Iron is especially a cofactor for DNA polymerases, primases, and ribonucleotide reductase. Iron is also globally involved in mitosis and meiosis processes. Alterations of iron cell homeostasis, whatever the causes are, including mutations in iron-related genes, lead both to the variation in the activities of those key enzymes of DNA replication and DNA repair, and to the production of reactive oxygen species (ROS), altogether resulting in genome instability and ultimately favoring malignancy.

\section{REFERENCES}

1. Brissot P. [Iron Overload: Better Understanding, Better Care]. Rev Prat. 2015;65(10):1305-11.

2. Pigeon $C$, llyin $G$, Courselaud $B$, Leroyer $P$, Turlin B, Brissot $P$, et al. A new mouse liver-specific gene, encoding a protein homologous to human antimicrobial peptide hepcidin, is overexpressed during iron overload. J Biol Chem. 2001;276(11):7811-9.

3. Nicolas G, Bennoun M, Devaux I, Beaumont C, Grandchamp B, Kahn A, et al. Lack of hepcidin gene expression and severe tissue iron overload in upstream stimulatory factor 2 (USF2) knockout mice. Proc Natl Acad Sci U S A. 2001;98(15):8780-5.

4. Ganz T. Systemic iron homeostasis. Physiological reviews. 2013;93(4):1721-41.

5. Muckenthaler MU, Galy B, Hentze MW. Systemic iron homeostasis and the iron-responsive element/iron-regulatory protein (IRE/IRP) regulatory network. Annu Rev Nutr. 2008;28:197-213.

6. Clark SF. Iron deficiency anemia. Nutr Clin Pract. 2008;23(2):128-41. 
7. Adams PC, Deugnier Y, Moirand R, Brissot P. The relationship between iron overload, clinical symptoms, and age in 410 patients with genetic hemochromatosis. Hepatology. 1997;25(1):162-6.

8. Porter JB, Garbowski M. The pathophysiology of transfusional iron overload. Hematol Oncol Clin North Am. 2014;28(4):683-701, vi.

9. Martelli A, Puccio H. Dysregulation of cellular iron metabolism in Friedreich ataxia: from primary iron-sulfur cluster deficit to mitochondrial iron accumulation. Front Pharmacol. 2014;5:130.

10. Peña-Rosas JP, Rogers L and Steven GA. The global prevalence of anaemia in 2011: WHO global database on anaemia. 2015. Editors. Geneva: WHO Press, World Health Organization; 2015.

11. Alkhateeb AA, Connor JR. Nuclear ferritin: A new role for ferritin in cell biology. Biochim Biophys Acta. 2010;1800(8):793-7.

12. Pigeon C, Turlin B, lancu TC, Leroyer P, Le Lan J, Deugnier Y, et al. Carbonyl-iron supplementation induces hepatocyte nuclear changes in BALB/CJ male mice. J Hepatol. 1999;30(5):926-34.

13. Pountney D, Trugnan G, Bourgeois M, Beaumont $C$. The identification of ferritin in the nucleus of $\mathrm{K} 562$ cells, and investigation of a possible role in the transcriptional regulation of adult beta-globin gene expression. J Cell Sci. 1999;112 ( Pt 6):825-31.

14. Netz DJ, Stith CM, Stumpfig M, Kopf G, Vogel D, Genau HM, et al. Eukaryotic DNA polymerases require an iron-sulfur cluster for the formation of active complexes. Nature chemical biology. 2011;8(1):125-32.

15. Wu Y, Brosh RM, Jr. DNA helicase and helicase-nuclease enzymes with a conserved iron-sulfur cluster. Nucleic Acids Res. 2012;40(10):4247-60.

16. Pra D, Franke SI, Henriques JA, Fenech M. Iron and genome stability: an update. Mutat Res. 2012;733(1-2):92-9.

17. Zhang C. Essential functions of iron-requiring proteins in DNA replication, repair and cell cycle control. Protein Cell. 2014;5(10):750-60.

18. Koc A, Wheeler L, Mathews CK, Merrill GF. Hydroxyurea arrests DNA replication by a mechanism that preserves basal dNTP pools. J Biol Chem. 2004;279(1):223-30.

19. Skoog L, Nordenskjold B. Effects of hydroxyurea and 1-beta-D-arabinofuranosyl-cytosine on deoxyribonucleotide pools in mouse embryo cells. Eur J Biochem. 1971;19(1):81-9.

20. Adams RL, Berryman S, Thomson A. Deoxyribonucleoside triphosphate pools in synchronized and drug-inhibited L 929 cells. Biochim Biophys Acta. 1971;240(4):455-62.

21. Snyder RD. The role of deoxynucleoside triphosphate pools in the inhibition of DNA-excision repair and replication in human cells by hydroxyurea. Mutat Res. 1984;131(3-4):163-72.

22. Gandhi V, Plunkett W, Kantarjian H, Talpaz M, Robertson LE, O'Brien S. Cellular pharmacodynamics and plasma pharmacokinetics of parenterally infused hydroxyurea during a phase I clinical trial in chronic myelogenous leukemia. J Clin Oncol. 1998;16(7):2321-31.

23. Kumar D, Viberg J, Nilsson AK, Chabes A. Highly mutagenic and severely imbalanced dNTP pools can escape detection by the S-phase checkpoint. Nucleic Acids Res. 2010;38(12):3975-83.

24. Ouameur AA, Arakawa H, Ahmad R, Naoui M, Tajmir-Riahi HA. A Comparative study of Fe(II) and $\mathrm{Fe}(\mathrm{III})$ interactions with DNA duplex: major and minor grooves bindings. DNA Cell Biol. 2005;24(6):394401.

25. Bertoncini C, Galembeck F, Calio M, Carbonel A. Preferential localization of iron in the chromatin of Fe-enriched cells linked toDNA cleavage sites and control of carcinogenesis. J Cancer Sci Ther. 2016(8):213-5.

26. Marsden MP, Laemmli UK. Metaphase chromosome structure: evidence for a radial loop model. Cell. 1979;17(4):849-58.

27. Rai $\mathrm{P}$, Cole TD, Wemmer DE, Linn S. Localization of $\mathrm{Fe}(2+)$ at an RTGR sequence within a DNA duplex explains preferential cleavage by Fe(2+) and H2O2. J Mol Biol. 2001;312(5):1089-101.

28. Henle ES, Han Z, Tang N, Rai P, Luo Y, Linn S. Sequence-specific DNA cleavage by Fe2+-mediated fenton reactions has possible biological implications. J Biol Chem. 1999;274(2):962-71.

29. Brown KE, Meleah Mathahs M, Broadhurst KA, Coleman MC, Ridnour LA, Schmidt WN, et al. Increased hepatic telomerase activity in a rat model of iron overload: a role for altered thiol redox state? Free Radic Biol Med. 2007;42(2):228-35. 
30. Mainous AG, 3rd, Wright RU, Hulihan MM, Twal WO, McLaren CE, Diaz VA, et al. Elevated transferrin saturation, health-related quality of life and telomere length. Biometals. 2014;27(1):135-41.

31. Mainous AG, 3rd, Wright RU, Hulihan MM, Twal WO, McLaren CE, Diaz VA, et al. Telomere length and elevated iron: the influence of phenotype and HFE genotype. Am J Hematol. 2013;88(6):4926.

32. Kepinska $M$, Szyller J, Milnerowicz $H$. The influence of oxidative stress induced by iron on telomere length. Environ Toxicol Pharmacol. 2015;40(3):931-5.

33. Troadec MB, Courselaud B, Detivaud L, Haziza-Pigeon C, Leroyer P, Brissot P, et al. Iron overload promotes Cyclin D1 expression and alters cell cycle in mouse hepatocytes. J Hepatol. 2006;44(2):391-9.

34. Chenoufi N, Loreal O, Drenou B, Cariou S, Hubert N, Leroyer P, et al. Iron may induce both DNA synthesis and repair in rat hepatocytes stimulated by EGF/pyruvate. J Hepatol. 1997;26(3):650-8.

35. Deugnier Y, Turlin B. Iron and hepatocellular carcinoma. J Gastroenterol Hepatol. 2001;16(5):491-4.

36. Deugnier YM, Charalambous P, Le Quilleuc D, Turlin B, Searle J, Brissot P, et al. Preneoplastic significance of hepatic iron-free foci in genetic hemochromatosis: a study of 185 patients. Hepatology. 1993;18(6):1363-9.

37. Troadec MB, Glaise D, Lamirault G, Le Cunff M, Guerin E, Le Meur N, et al. Hepatocyte iron loading capacity is associated with differentiation and repression of motility in the HepaRG cell line. Genomics. 2006;87(1):93-103.

38. Le NT, Richardson DR. The role of iron in cell cycle progression and the proliferation of neoplastic cells. Biochim Biophys Acta. 2002;1603(1):31-46.

39. Gao J, Richardson DR. The potential of iron chelators of the pyridoxal isonicotinoyl hydrazone class as effective antiproliferative agents, IV: The mechanisms involved in inhibiting cell-cycle progression. Blood. 2001;98(3):842-50.

40. Kulp KS, Green SL, Vulliet PR. Iron deprivation inhibits cyclin-dependent kinase activity and decreases cyclin D/CDK4 protein levels in asynchronous MDA-MB-453 human breast cancer cells. Exp Cell Res. 1996;229(1):60-8.

41. Yu H, Guo P, Xie X, Wang Y, Chen G. Ferroptosis, a new form of cell death, and its relationships with tumourous diseases. J Cell Mol Med. 2017;21(4):648-57.

42. Brault A, Rallis C, Normant V, Garant JM, Bahler J, Labbe S. Php4 Is a Key Player for Iron Economy in Meiotic and Sporulating Cells. G3 (Bethesda). 2016;6(10):3077-95.

43. Mercier A, Watt S, Bahler J, Labbe S. Key function for the CCAAT-binding factor Php4 to regulate gene expression in response to iron deficiency in fission yeast. Eukaryot Cell. 2008;7(3):493-508.

44. Troadec MB, Fautrel A, Drenou B, Leroyer P, Camberlein E, Turlin B, et al. Transcripts of ceruloplasmin but not hepcidin, both major iron metabolism genes, exhibit a decreasing pattern along the portocentral axis of mouse liver. Biochim Biophys Acta. 2008;1782(4):239-49.

45. Kuvibidila S, Porretta C, Baliga S. Aneuploidy assessed by DNA index influences the effect of iron status on plasma and/or supernatant cytokine levels and progression of cells through the cell cycle in a mouse model. Cytokine. 2014;65(2):175-83.

46. Imlay JA. Pathways of oxidative damage. Annu Rev Microbiol. 2003;57:395-418.

47. Abalea V, Cillard J, Dubos MP, Sergent O, Cillard P, Morel I. Repair of iron-induced DNA oxidation by the flavonoid myricetin in primary rat hepatocyte cultures. Free Radic Biol Med. 1999;26(1112):1457-66.

48. Gao X, Campian JL, Qian M, Sun XF, Eaton JW. Mitochondrial DNA damage in iron overload. J Biol Chem. 2009;284(8):4767-75.

49. Zhong Y, Onuki J, Yamasaki T, Ogawa O, Akatsuka S, Toyokuni S. Genome-wide analysis identifies a tumor suppressor role for aminoacylase 1 in iron-induced rat renal cell carcinoma. Carcinogenesis. 2009;30(1):158-64.

50. Kew MC. Hepatic iron overload and hepatocellular carcinoma. Liver cancer. 2014;3(1):31-40.

51. Funakoshi N, Chaze I, Alary AS, Tachon G, Cunat S, Giansily-Blaizot M, et al. The role of genetic factors in patients with hepatocellular carcinoma and iron overload - a prospective series of 234 patients. Liver Int. 2016;36(5):746-54. 
52. Moukhadder HM, Halawi R, Cappellini MD, Taher AT. Hepatocellular carcinoma as an emerging morbidity in the thalassemia syndromes: A comprehensive review. Cancer. 2016.

53. Elmberg M, Hultcrantz R, Ekbom A, Brandt L, Olsson S, Olsson R, et al. Cancer risk in patients with hereditary hemochromatosis and in their first-degree relatives. Gastroenterology. 2003;125(6):1733-41.

54. Bardou-Jacquet E, Morcet J, Manet G, Laine F, Perrin M, Jouanolle AM, et al. Decreased cardiovascular and extrahepatic cancer-related mortality in treated patients with mild HFE hemochromatosis. J Hepatol. 2015;62(3):682-9.

55. Vautier G, Bomford AB, Portmann BC, Metivier E, Williams R, Ryder SD. p53 mutations in british patients with hepatocellular carcinoma: clustering in genetic hemochromatosis. Gastroenterology. 1999;117(1):154-60.

56. Hussain SP, Raja K, Amstad PA, Sawyer M, Trudel LJ, Wogan GN, et al. Increased p53 mutation load in nontumorous human liver of wilson disease and hemochromatosis: oxyradical overload diseases. Proc Natl Acad Sci U S A. 2000;97(23):12770-5.

57. Silva AE, Manzato AJ, Varella-Garcia M. Sister-chromatid exchanges in beta-thalassaemic patients under conditions of in vivo and in vitro depletion of folic acid. Mutat Res. 1992;282(3):213-7.

58. Al-Sweedan SA, Khabour O, Isam R. Genotoxicity assessment in patients with thalassemia minor. Mutat Res. 2012;744(2):167-71.

59. Cote GB, Papadakou-Lagoyanni S. Beta-thalassaemia: increased chromosomal anomalies in lymphocyte cultures. J Med Genet. 1979;16(1):52-5.

60. McDonald CJ, Ostini L, Wallace DF, John AN, Watters DJ, Subramaniam VN. Iron loading and oxidative stress in the Atm-/- mouse liver. Am J Physiol Gastrointest Liver Physiol. 2011;300(4):G554-60.

61. Maciejczyk M, Mikoluc B, Pietrucha B, Heropolitanska-Pliszka E, Pac M, Motkowski R, et al. Oxidative stress, mitochondrial abnormalities and antioxidant defense in Ataxia-telangiectasia, Bloom syndrome and Nijmegen breakage syndrome. Redox Biol. 2017;11:375-83.

62. Shackelford RE, Fu Y, Manuszak RP, Brooks TC, Sequeira AP, Wang S, et al. Iron chelators reduce chromosomal breaks in ataxia-telangiectasia cells. DNA Repair (Amst). 2006;5(11):1327-36.

63. Adachi S, Takemoto K, Hirosue T, Hosogai Y. Spontaneous and 2-nitropropane induced levels of 8-hydroxy-2'-deoxyguanosine in liver DNA of rats fed iron-deficient or manganese- and copper-deficient diets. Carcinogenesis. 1993;14(2):265-8.

64. Walter PB, Knutson MD, Paler-Martinez A, Lee $S, X u Y$, Viteri FE, et al. Iron deficiency and iron excess damage mitochondria and mitochondrial DNA in rats. Proc Natl Acad Sci U S A. 2002;99(4):22649.

65. Diaz-Castro J, Alferez MJ, Lopez-Aliaga I, Nestares T, Granados S, Barrionuevo M, et al. Influence of nutritional iron deficiency anemia on DNA stability and lipid peroxidation in rats. Nutrition. 2008;24(11-12):1167-73.

66. Walter T. Effect of iron-deficiency anemia on cognitive skills and neuromaturation in infancy and childhood. Food Nutr Bull. 2003;24(4 Suppl):S104-10.

67. Aslan M, Horoz M, Kocyigit A, Ozgonul S, Celik H, Celik M, et al. Lymphocyte DNA damage and oxidative stress in patients with iron deficiency anemia. Mutat Res. 2006;601(1-2):144-9.

68. Aksu BY, Hasbal C, Himmetoglu S, Dincer Y, Koc EE, Hatipoglu S, et al. Leukocyte DNA damage in children with iron deficiency anemia: effect of iron supplementation. Eur J Pediatr. 2010;169(8):951-6.

69. Khabour OF, Soudah OA, Aaysh MH. Genotoxicity assessment in iron deficiency anemia patients using sister chromatid exchanges and chromosomal aberrations assays. Mutat Res. 2013;750(1-2):72-6.

70. Brissot $\mathrm{P}$, Loreal $\mathrm{O}$. Iron metabolism and related genetic diseases: A cleared land, keeping mysteries. J Hepatol. 2016;64(2):505-15.

71. Feder JN, Gnirke A, Thomas W, Tsuchihashi Z, Ruddy DA, Basava A, et al. A novel MHC class I-like gene is mutated in patients with hereditary haemochromatosis. Nature genetics. 1996;13(4):399-408.

72. Cezard C, Rabbind Singh A, Le Gac G, Gourlaouen I, Ferec C, Rochette J. Phenotypic expression of a novel C282Y/R226G compound heterozygous state in HFE hemochromatosis: molecular dynamics and biochemical studies. Blood Cells Mol Dis. 2014;52(1):27-34. 
73. Piubelli C, Castagna A, Marchi G, Rizzi M, Busti F, Badar S, et al. Identification of new BMP6 propeptide mutations in patients with iron overload. Am J Hematol. 2017;92(6):562-8.

74. Daher R, Kannengiesser C, Houamel D, Lefebvre T, Bardou-Jacquet E, Ducrot $N$, et al. Heterozygous Mutations in BMP6 Pro-peptide Lead to Inappropriate Hepcidin Synthesis and Moderate Iron Overload in Humans. Gastroenterology. 2016;150(3):672-83 e4.

75. Meynard D, Kautz L, Darnaud V, Canonne-Hergaux F, Coppin H, Roth MP. Lack of the bone morphogenetic protein BMP6 induces massive iron overload. Nat Genet. 2009;41(4):478-81.

76. Roetto A, Papanikolaou G, Politou M, Alberti F, Girelli D, Christakis J, et al. Mutant antimicrobial peptide hepcidin is associated with severe juvenile hemochromatosis. Nat Genet. 2003;33(1):21-2.

77. Camaschella C, Roetto A, Cali A, De Gobbi M, Garozzo G, Carella M, et al. The gene TFR2 is mutated in a new type of haemochromatosis mapping to 7q22. Nat Genet. 2000;25(1):14-5.

78. Njajou OT, Vaessen N, Joosse M, Berghuis B, van Dongen JW, Breuning MH, et al. A mutation in SLC11A3 is associated with autosomal dominant hemochromatosis. Nature genetics. 2001;28(3):213-4.

79. Montosi G, Donovan A, Totaro A, Garuti C, Pignatti E, Cassanelli S, et al. Autosomal-dominant hemochromatosis is associated with a mutation in the ferroportin (SLC11A3) gene. J Clin Invest. 2001;108(4):619-23.

80. Miyajima H. Aceruloplasminemia. Neuropathology : official journal of the Japanese Society of Neuropathology. 2015;35(1):83-90.

81. Loreal O, Cavey T, Bardou-Jacquet E, Guggenbuhl P, Ropert M, Brissot P. Iron, hepcidin, and the metal connection. Front Pharmacol. 2014;5:128.

82. Hershko C, Graham G, Bates GW, Rachmilewitz EA. Non-specific serum iron in thalassaemia: an abnormal serum iron fraction of potential toxicity. Br J Haematol. 1978;40(2):255-63.

83. Brissot $\mathrm{P}$, Ropert $\mathrm{M}$, Le Lan $\mathrm{C}$, Loreal $\mathrm{O}$. Non-transferrin bound iron: a key role in iron overload and iron toxicity. Biochim Biophys Acta. 2012;1820(3):403-10.

84. Brissot P. Optimizing the diagnosis and the treatment of iron overload diseases. Expert Rev Gastroenterol Hepatol. 2016;10(3):359-70.

85. Le Lan C, Mosser A, Ropert M, Detivaud L, Loustaud-Ratti V, Vital-Durand D, et al. Sex and acquired cofactors determine phenotypes of ferroportin disease. Gastroenterology. 2011;140(4):1199207 e1-2.

86. Aslan D, Crain K, Beutler E. A new case of human atransferrinemia with a previously undescribed mutation in the transferrin gene. Acta Haematol. 2007;118(4):244-7.

87. Iolascon A, d'Apolito M, Servedio V, Cimmino F, Piga A, Camaschella C. Microcytic anemia and hepatic iron overload in a child with compound heterozygous mutations in DMT1 (SCL11A2). Blood. 2006;107(1):349-54.

88. Bardou-Jacquet $E$, Island ML, Jouanolle AM, Detivaud L, Fatih N, Ropert $M$, et al. A novel N491S mutation in the human SLC11A2 gene impairs protein trafficking and in association with the G212V mutation leads to microcytic anemia and liver iron overload. Blood Cells Mol Dis. 2011;47(4):243-8.

89. Kono S. Aceruloplasminemia: an update. International review of neurobiology. 2013;110:125-51.

90. Schipper HM. Neurodegeneration with brain iron accumulation - clinical syndromes and neuroimaging. Biochim Biophys Acta. 2012;1822(3):350-60.

91. Zhou B, Westaway SK, Levinson B, Johnson MA, Gitschier J, Hayflick SJ. A novel pantothenate kinase gene (PANK2) is defective in Hallervorden-Spatz syndrome. Nat Genet. 2001;28(4):345-9.

92. Curtis AR, Fey C, Morris CM, Bindoff LA, Ince PG, Chinnery PF, et al. Mutation in the gene encoding ferritin light polypeptide causes dominant adult-onset basal ganglia disease. Nat Genet. 2001;28(4):350-4.

93. Morgan NV, Westaway SK, Morton JE, Gregory A, Gissen P, Sonek S, et al. PLA2G6, encoding a phospholipase $A 2$, is mutated in neurodegenerative disorders with high brain iron. Nat Genet. 2006;38(7):752-4.

94. Bottomley SS, Fleming MD. Sideroblastic anemia: diagnosis and management. Hematol Oncol Clin North Am. 2014;28(4):653-70, v.

95. Visconte V, Rogers HJ, Singh J, Barnard J, Bupathi M, Traina F, et al. SF3B1 haploinsufficiency leads to formation of ring sideroblasts in myelodysplastic syndromes. Blood. 2012;120(16):3173-86. 
96. Zhu Y, Li X, Chang C, Xu F, He Q, Guo J, et al. SF3B1-mutated myelodysplastic syndrome with ring sideroblasts harbors more severe iron overload and corresponding over-erythropoiesis. Leuk Res. 2016;44:8-16.

97. Finberg KE, Heeney MM, Campagna DR, Aydinok Y, Pearson HA, Hartman KR, et al. Mutations in TMPRSS6 cause iron-refractory iron deficiency anemia (IRIDA). Nat Genet. 2008;40(5):569-71.

98. Heeney MM, Finberg KE. Iron-refractory iron deficiency anemia (IRIDA). Hematol Oncol Clin North Am. 2014;28(4):637-52, v.

99. Poggiali E, Andreozzi F, Nava I, Consonni D, Graziadei G, Cappellini MD. The role of TMPRSS6 polymorphisms in iron deficiency anemia partially responsive to oral iron treatment. Am J Hematol. 2015;90(4):306-9.

100. Girelli D, Corrocher R, Bisceglia L, Olivieri O, De Franceschi L, Zelante L, et al. Molecular basis for the recently described hereditary hyperferritinemia-cataract syndrome: a mutation in the ironresponsive element of ferritin L-subunit gene (the "Verona mutation"). Blood. 1995;86(11):4050-3.

101. Beaumont C, Leneuve P, Devaux I, Scoazec JY, Berthier M, Loiseau MN, et al. Mutation in the iron responsive element of the $L$ ferritin mRNA in a family with dominant hyperferritinaemia and cataract. Nat Genet. 1995;11(4):444-6.

102. Kannengiesser C, Jouanolle AM, Hetet G, Mosser A, Muzeau F, Henry D, et al. A new missense mutation in the $L$ ferritin coding sequence associated with elevated levels of glycosylated ferritin in serum and absence of iron overload. Haematologica. 2009;94(3):335-9.

103. Troadec MB, Warner D, Wallace J, Thomas K, Spangrude GJ, Phillips J, et al. Targeted deletion of the mouse Mitoferrin1 gene: from anemia to protoporphyria. Blood. 2011;117(20):5494-502.

104. Wang Y, Langer NB, Shaw GC, Yang G, Li L, Kaplan J, et al. Abnormal mitoferrin-1 expression in patients with erythropoietic protoporphyria. Exp Hematol. 2011;39(7):784-94.

105. Fuqua BK, Lu Y, Darshan D, Frazer DM, Wilkins SJ, Wolkow N, et al. The multicopper ferroxidase hephaestin enhances intestinal iron absorption in mice. PLoS One. 2014;9(6):e98792.

106. Nuttle X, Giannuzzi G, Duyzend MH, Schraiber JG, Narvaiza I, Sudmant PH, et al. Emergence of a Homo sapiens-specific gene family and chromosome 16p11.2 CNV susceptibility. Nature. 2016;536(7615):205-9.

107. Banci L, Camponeschi F, Ciofi-Baffoni S, Muzzioli R. Elucidating the Molecular Function of Human BOLA2 in GRX3-Dependent Anamorsin Maturation Pathway. J Am Chem Soc. 2015;137(51):16133-43.

108. Leidgens S, Bullough KZ, Shi H, Li F, Shakoury-Elizeh M, Yabe T, et al. Each member of the poly$\mathrm{r}(\mathrm{C})$-binding protein 1 (PCBP) family exhibits iron chaperone activity toward ferritin. J Biol Chem. 2013;288(24):17791-802.

109. Dixon SJ. Ferroptosis: bug or feature? Immunol Rev. 2017;277(1):150-7. 


\begin{tabular}{lcllc}
\hline Type & Chromosome & Gene & Phenotype & Mode of \\
& & & & transmission \\
\hline Hemochromatosis & & & & \\
& & & & \\
1 & 1 & $H F E$ & $10(\mathrm{HD})$ & $\mathrm{R}$ \\
$2 \mathrm{~A}$ & & HFE2 & $10(\mathrm{HD})$ & $\mathrm{R}$ \\
$2 \mathrm{~B}$ & 19 & (HJV) & & $\mathrm{R}$ \\
3 & 7 & HAMP & $10(\mathrm{HD})$ & $\mathrm{R}$ \\
4 & 2 & TFR2 & $10(\mathrm{HD})$ & $\mathrm{D}$ \\
\hline
\end{tabular}

Other types of genetic iron-related disorders

$\begin{array}{cclll} & 3 & C P & \text { An }+10 & \mathrm{R} \\ & 3 & T F & \text { An }+10 & \mathrm{R} \\ \text { Aceruloplasminemia } & 22 & \text { TMPRSS6 } & \text { An + ID } & \mathrm{R} \\ & 19 & \text { FTL } & \text { Neither IO nor ID } & \text { D }\end{array}$

Atransferrinemia

IRIDA

Ferritin-cataract syndrome

Table 1. Classification of main genetic iron-related disorders. 
An: anemia. CP: ceruloplasmin. D: dominant mode of transmission. FTL: ferritin light chain. HAMP: hepcidin. HD: hepcidin deficient phenotype. HJV: hemojuvelin. ID: iron deficiency. IO: iron overload. IRIDA: iron refractory iron deficiency anemia. R: recessive mode of transmission. SLC40A1: ferroportin. TF: transferrin. TFR2: transferrin receptor2. TMPRSS6: transmembrane protein, serine 6. 


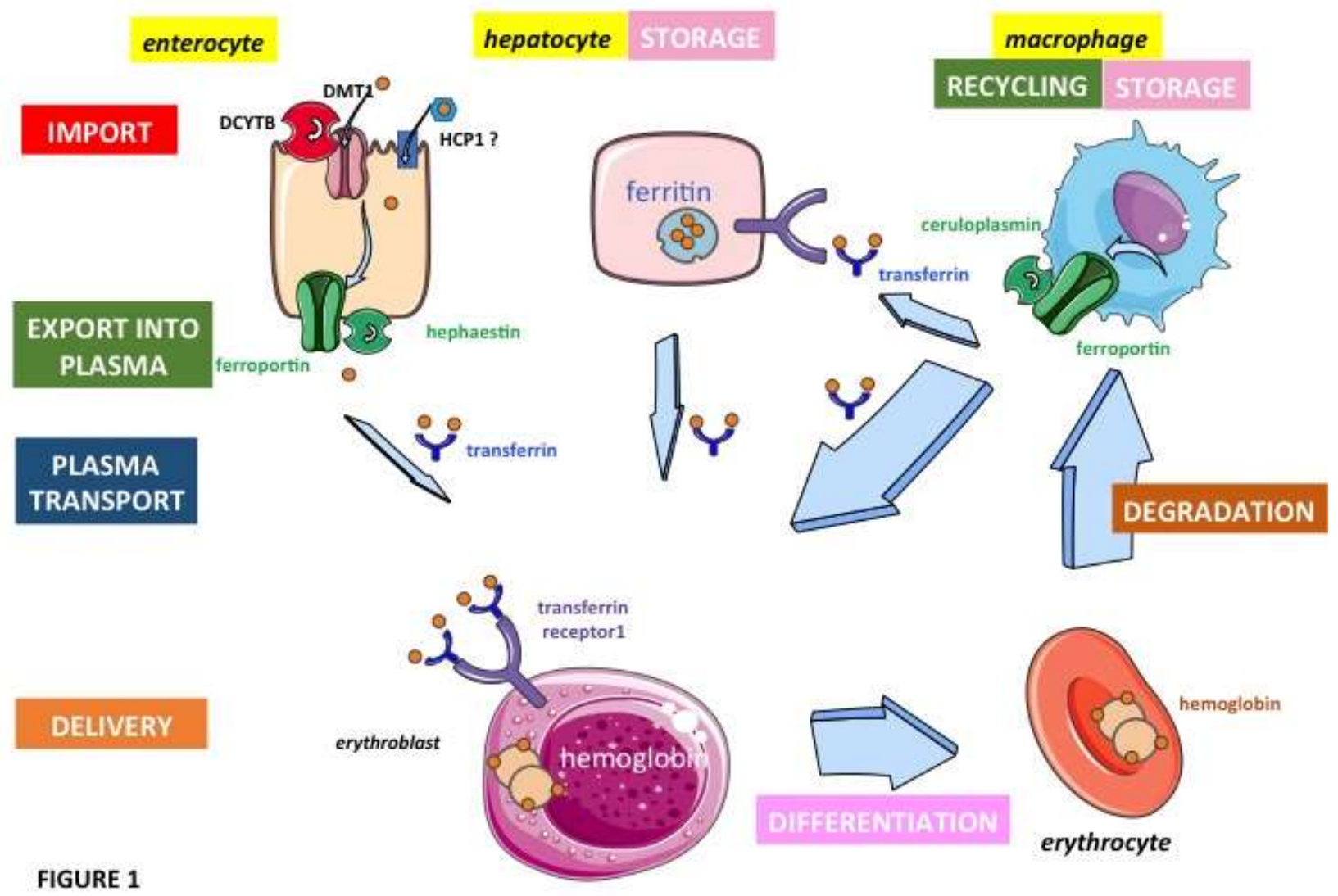


FIGURE 2

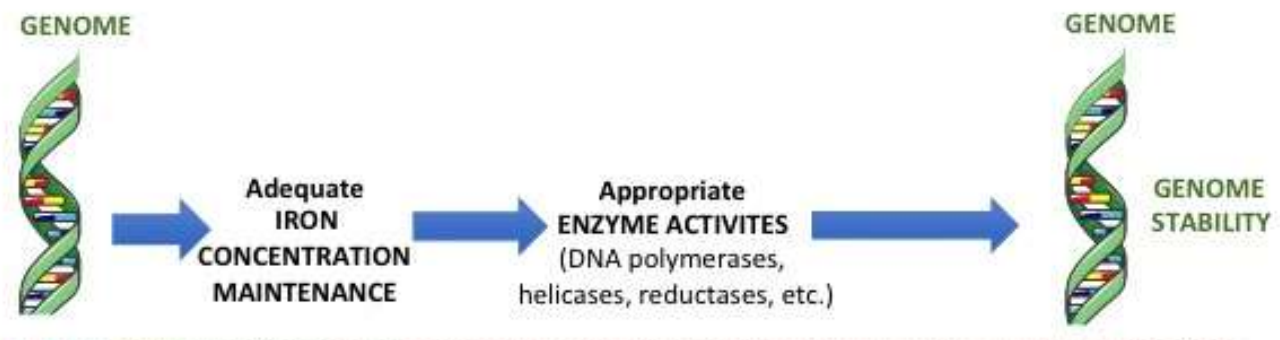

Mutations in

iron-related genes
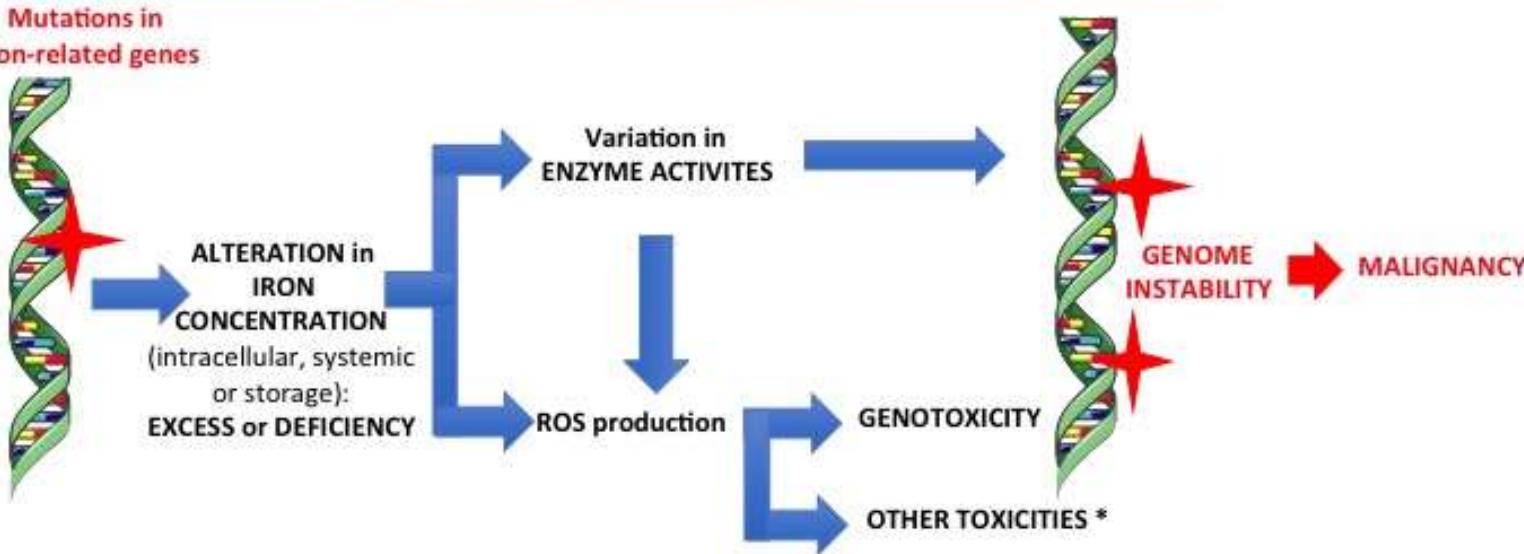

* Are not the purpose of the review 